\title{
Regional inequality of resident income and its determinants: A case study of Zhejiang Province, China
}

\author{
Qinchen Zhang $\mathbb{D}$
}

Accepted: 14 June 2021 / Published online: 20 June 2021

(C) The Author(s) 2021

\begin{abstract}
This paper focuses on the regional inequality of resident income in local China at the county or district level, and Zhejiang Province is set as the empirical case. It takes a geographic approach to detect the spatial distribution pattern of resident income, and explore the relationship with regionalspecific socio-economic factors. The analytical framework proposed by us has been proved appropriate by the case study. Our study results show that in terms of the resident income level, there exists great regional gap in Zhejiang with the northeast wealthy cluster and much poorer cluster in the southwest. The disposable income of residents is mainly determined by commerce prosperity, urban intensity and technological capacity of local areas, while the effect of regional income, household deposits and industrial production are much less or no significant. Our findings for Zhejiang lead us to suggest that those local states seeking to improve people's livelihood and income should not solely rely on the industrial or manufacturing expansion, but pay more attention to business environment, urban construction and indigenous innovation. Also, to narrow the significant regional gap of resident income, extra efforts should be made to push
\end{abstract}

Q. Zhang ( $\square)$

School of Natural and Built Environment, Queen's

University Belfast, Elmwood Avenue, Belfast BT7 1NN,

UK

e-mail: qzhang19@qub.ac.uk the regional cooperation system in economic development.

Keywords Regional inequality - Resident income · Influencing factors $\cdot$ Zhejiang $\cdot$ China

\section{Introduction}

Income inequality is a socio-economic issue of global concern. The neoclassical convergence hypothesis summarizes the general law of its evolution, but the explanation for developing countries or transition economies is often unsatisfactory (Wei et al., 2017). In China, due to the unique economic structure and domestic environment, the problem of inequality is particularly prominent and complicated. The prevailing view is that the steep rise in income inequality of China is closely related to economic reforms (Gao et al., 2019a, b; Sutherland \& Yao, 2011; Xie \& Zhou, 2014). The transition from a planned economy to a market-oriented one consequences a surge in the inequality of national income distribution with obvious rise in Gini index (Molero-Simarro, 2017). According to Barry Naughton (2007) "there may be no other case where a society's income distribution has deteriorated so much, so fast". Although the distribution system is often regarded as the fundamental cause (Zhang, 2020), some specific situations 
and realistic reasons for income inequality have also attracted scholars' attention such as urbanization (Wang et al., 2019a, b; Yuan et al., 2020), financial development (Li, 2020; Su et al., 2019), administrative management (Zeng et al., 2018) and social policy (Gao et al., 2019a, b). Wang et al. (2014) discussed profiles of income inequality in China along three dimensions: interhousehold disparity, regional divides, and urbanrural gaps. They examined the wide driving forces behind rising inequality including policy biases, location or geographic factors, globalization, and education, as well as the effect of government interventions.

The interhousehold disparity is considered as the micro source and basic form of income inequality in China, and relevant study has been widely conducted (Anderson et al., 2019; Li \& Sicular, 2014; Xie \& Jin, 2015). Paul et al. (2017) investigated the effects of household income sources on the level and rise of inequality in urban China, based on the householdlevel data from the Chinese Household Income Project Surveys (CHIPS). Their empirical results show the contribution of wages and salaries to inequality has declined over the years, but business income also has turned into an inequality reducing force after the middle 1990s. It has many implications for the policy options or intervention to narrow the interhousehold disparity. Household income inequality in rural areas also got much attention, and it is found associated with some different factors like agricultural activities, ecological protection projects, and farmers' physical assets (Leng et al., 2020; Xiang et al., 2020; Zhang et al., 2019). Zhang et al. (2019) believe local off-farm work and out-migration with remittances are the two principal income sources and both add to inequality. Although human capital, natural capital and physical capital all play roles in the generation of income and inequality in rural China, the factors affecting inequality from agricultural and non-agricultural activities are different.

Apart from the interhousehold disparity, urbanrural gap and regional inequality are much more intuitive in China, and show diverse spatial patterns with great significance. Wu and $\mathrm{He}$ (2018) pointed out urban-rural gap and regional inequality are longstanding problems in China and result in considerable number of studies. Their empirical results indicate the dominant characteristics in the income distribution dynamics, that persistence and immobility, as well as the separate convergence clubs in urban and rural areas. The pattern of urban-rural gap proves in three regional groups, namely the eastern, central and western regions, and geographical poverty traps exist in both urban and rural prefectural areas. Tian et al. (2016) revisited the regional income inequality in China comprehensively, from a perspective of club convergence. They found more interesting geographic patterns that instead of one convergence at the national level, provincial incomes are converging into two clubs: seven east-coastal provinces (Shanghai, Tianjin, Jiangsu, Zhejiang, Guangdong, Shandong, and Fujian) and Inner Mongolia are converging into a high-income club, and the remaining provinces are converging into a low-income club.

In particular, the urban-rural gap is regarded as a significant factor with impacts on income distribution in China (Luo et al., 2020; Wang et al., 2020). Many scholars believe there is no developing country whose income gap between urban and rural areas contributes more to overall income inequality than China's. According to the WORLD INEQUALITY REPORT 2018, the urban-rural gap of China continues to grow in the past decades, but it is within-region inequality that spurs overall growth in inequality. It also shows despite the increase of inequality both in urban and rural China, the level of income inequality in China as a whole is markedly higher at the national level than it is within urban China or rural China considered alone. Ma et al. (2018) investigated income inequality between rural and urban residents in the reforming era of China based on both urban-rural flow and the accumulated income Gini coefficient. They demonstrated the positive effect of urbanization process on the decline of the Gini coefficient.

In this paper, we focus on the regional inequality of resident income in local China that is the county or district level. The purpose is to investigate the effect of spatial heterogeneity on resident income and its association with regional-specific factors. The conception of resident income is defined as per capita disposable household income, and we believe it is interrelated with the uneven spatial development in China. Although the issue of our study still belongs to the category of regional inequality (Liao et al., 2020), the urban-rural gap can also get involved for discussion within the analytical framework due to the different built-up levels of local areas. The study aims to contribute to an enhanced understanding of 
geographic distribution pattern of resident income levels and its relationship with regional-specific factors in local China. As few studies take the approach like us, it can hopefully enrich the relevant empirical results. In the practice, we will establish an evaluation system based on statistical data at the county and district level in China, and then take Zhejiang Province as an example for testing and analysis.

\section{Theoretical framework}

As mentioned previously, there have been numerous literatures reporting the income inequality research in China. As far as regional inequality is concerned, most studies are based on the measurement and analysis of per capita gross domestic product (GDP per capita) and the added value, or so-called per capita national income (He et al., 2019; Huang \& Wei, 2019; Li \& Fang, 2014). This indicator undoubtedly has broad macroeconomic implications and can indeed reflect some essential feature of the regional economy, such as total factor productivity (TFP) (He et al., 2017a, b, c). However, it does not fully represent the people's livelihood and income. How to measure the income level of local residents in a reasonable manner and detect such income inequality spatially is the motivation of our research. Another consideration is the geographic scale. The interregional or interprovincial inequality across the country has been extensively examined and summarized as the east-west gap and coastal-inland gap (Hao \& Wei, 2010; He et al., $2017 \mathrm{a}, \mathrm{b}, \mathrm{c})$. But the intra-provincial inequality is still less known in China, and few studies are conducted in such smaller scale. The spatial association or geographic pattern of the income distribution in a fine distance thus deserves further research.

As such, this study adopts a geographic-economy framework to assess the regional inequality of resident income in local China. The geographic aspect focuses on the effect of spatial heterogeneity on the income level of residents. It aims to explore the regional differences of resident income and the potential pattern of the geographic distribution. The economy perspective is dedicated to understanding the spatial interrelations among regional development, economic prosperity and people's livelihood. Most people are engaged in various economic activities in the locality to make life and acquire wealth from the society. So, the regional macroeconomic performance is generally regarded to have the positive relationship with resident income. And it happens through the numerous humaneconomy interaction channels such as wage labour, business operation and financial investment. On the whole, the integrative works attempt to seek a socioeconomic explanation for the geographic distribution pattern of resident income level. The quantitative analysis allows us to compare the contribution of different explanatory factors and find the major ones. At the same time, another purpose of our study is to provide some implications or advice for somewhere struggling in regional poverty or low-income status. We hope that the conclusions of this case can have a wide range of practical significance. As a small-scale empirical study, we pay particular attention to the spatial autocorrelation in the distribution of resident income and the relationship with geographic environment. The research methods, and background information of the study area will be given later.

\section{Methods}

\section{Data survey and mapping}

We use the indicator of per capita disposable household income (DHIN per capita) to measure the income level of residents in local areas of China. It is an important item of household sample surveys conducted by statistical departments across China. The household sample survey conducted with each administrative area as an independent unit has two separate parts of urban and rural. But it has developed into an integrated version which no longer artificially distinguishes resident status in survey. This is a major statistical system reform that China promoted in 2012 in order to adapt to the development of urban-rural integration (Iacob, 2013). Disposable income is a conception different from national income. It refers to the amount of money that that all of the individuals in the household sector have available for spending or saving after income distribution measures (for example, taxes, social contributions and benefits) have taken effect. It comes from the fact-finding surveys and covers the sum of all income sources of the household including wages and salary income, net business income, net property income and net transfer 
income. So, the Index of DHIN per capita can well reveal the livelihood and average income of local residents.

We make a data mapping of DHIN per capita and geographic area on the ArcGIS platform, in order to analyse the geographic characteristics. The starting point of our thoughts is spatial economic agglomeration, a common phenomenon especially in China ( $\mathrm{Li}$ \& Li, 2018; Liu et al., 2018; Wei et al., 2020a, b), may consequence the spatial disparity of people's livelihood and income. This may be manifested in certain geographic pattern, such as spatial segregation, autocorrelation and clustering. To detect the effect of spatial heterogeneity, we will use Moran's I and GetisOrd General G statistics for the pattern analysis, and Hot Spot Analysis (Getis-Ord Gi*) for clusters mapping (Getis \& Ord, 2010; Mitchel, 2005; Wooldridge, 2006). It will quantitatively assess the spatial dependency of data distribution, and judge the pattern, clustered, random or dispersed, as well as high-low value clusters, based on significance statistics. As far as our study issue is concerned, it will help verify the geographic polarization and clustering of resident income which bonds with some tough problems in current China like unbalanced development, regional disparity and poverty.

\section{Analytical design and modeling}

The issue of regional inequality in resident income has long been a concern in China. Existing literatures have extensive explanations in the view of people's livelihoods, regional characteristics, and urban-rural differences, but they are rarely based on an integrated analysis. So, their results vary because different perspectives, methodologies and data sets are employed. Although most evidence proves reasonable, some conclusions are so partial without the covering of explanatory factors as much as possible. Using a data set in the most current of 89 local areas in Zhejiang, one of China's model province, in this paper we try a macro approach to find determinants of the regional inequality in resident income at county or district level, and we seek to explain how geographic heterogeneity has influenced resident livelihood or welfare, mainly manifested in disposable income. As the research samples involve both counties (a little built-up areas) and complete urban districts, the regional differences in the general sense and specific urban-rural divide can be incorporated into a unified empirical framework (Table 1). The theoretical starting point is the basic hypothesis that the vast majority of individuals obtain income from society by participating in various types of economic activities directly or indirectly, which can be roughly divided into production, commodity exchange (sales) and technological creation. The accumulation of existing wealth or assets will bring continuous returns and constitute part of the resident income generally. Besides, regional development and national wealth can cause an unignorable effect on the overall performance of all kinds of economic operations, which is expected to affect resident income as consequence. In this study, we posit disposable household income per capita (DHINpc) as the dependent variable and choose several explanatory variables with various impacts on resident income through major income sources including wage labor, business operation and deposits returns, as well as factors determining the economic performance (e.g., development stage, technology and urban-rural divide).

Variables

\section{Dependent variable}

1. Disposable household income per capita (DHINpc). This variable is derived from the per capita disposable income of urban and rural households, which has been widely regarded as one of the major indices of people's welfare or livelihood in China. As mentioned earlier, the data comes from the upgraded household sample survey, which no longer deliberately classifies residents as urban or rural. In the study, DHINpc denotes the average per capita income of all households in each county or district. We employ this variable to explore the geographic characteristics of resident income and examine regional determinants of income inequality in China at the county or district level.

\section{Independent variables}

2. Per capita regional domestic product (LRDPpc). Resident income often depends on regional economic development and the national income distribution. LRDPpc has been widely employed to examine the economic development of specific areas (He et al., , 
Table 1 Definitions of variables and data sources. Source: compiled by authors

\begin{tabular}{|c|c|c|c|c|}
\hline $\begin{array}{l}\text { Variable } \\
\text { (for local } \\
\text { areas) }\end{array}$ & Measurement & $\begin{array}{l}\text { Expected } \\
\text { sign with } \\
\text { DHINpc }\end{array}$ & $\begin{array}{l}\text { Theoretical } \\
\text { justification }\end{array}$ & Data source \\
\hline DHINpc & $\begin{array}{l}\text { Resident disposable income, defined by per } \\
\text { capita disposable income of urban and } \\
\text { rural households }\end{array}$ & N.A & N.A & $\begin{array}{l}\text { Annual Statistical Bulletin of Local Social } \\
\text { Economy; Statistical yearbooks of } \\
\text { Zhejiang and its sub-divided prefectures }\end{array}$ \\
\hline LRDPpc & $\begin{array}{l}\text { Regional national income, measured by } \\
\text { nominal per capita domestic product }\end{array}$ & + & $\begin{array}{l}\text { Development } \\
\text { and better } \\
\text { livelihood }\end{array}$ & $\begin{array}{l}\text { Statistical yearbooks of Zhejiang and its } \\
\text { sub-divided prefectures }\end{array}$ \\
\hline LHDPpc & $\begin{array}{l}\text { Household deposits per capita, defined by } \\
\text { the balance of savings deposits of rural and } \\
\text { urban residents divided by the de facto } \\
\text { population }\end{array}$ & + & $\begin{array}{l}\text { Assets and } \\
\text { capital return }\end{array}$ & $\begin{array}{l}\text { Statistical yearbooks of Zhejiang and its } \\
\text { sub-divided prefectures }\end{array}$ \\
\hline BUILTpc & $\begin{array}{l}\text { Built-up areas per capita, defined by the } \\
\text { square of built-up areas divided by the de } \\
\text { facto population }\end{array}$ & + & $\begin{array}{l}\text { Urban-rural } \\
\text { divide and } \\
\text { differences }\end{array}$ & $\begin{array}{l}\text { Statistical yearbooks of Zhejiang and its } \\
\text { sub-divided prefectures }\end{array}$ \\
\hline INDUS & $\begin{array}{l}\text { Industrial production, measured by the } \\
\text { output value of industrial enterprises above } \\
\text { designated size }\end{array}$ & + & $\begin{array}{l}\text { Labor and wage } \\
\text { income }\end{array}$ & $\begin{array}{l}\text { Statistical yearbooks of Zhejiang and its } \\
\text { sub-divided prefectures }\end{array}$ \\
\hline COMME & $\begin{array}{l}\text { Commerce scale and prosperity, measured } \\
\text { by the total retail sale of consumer goods }\end{array}$ & + & $\begin{array}{l}\text { Business and } \\
\text { operating } \\
\text { income }\end{array}$ & $\begin{array}{l}\text { Statistical yearbooks of Zhejiang and its } \\
\text { sub-divided prefectures }\end{array}$ \\
\hline TECHN & $\begin{array}{l}\text { Technological and innovative capacity, } \\
\text { measured by the number of annual patent } \\
\text { applications granted }\end{array}$ & + & $\begin{array}{l}\text { Innovation, } \\
\text { increased } \\
\text { productivity } \\
\text { and profits }\end{array}$ & $\begin{array}{l}\text { Statistical yearbooks of Zhejiang and its } \\
\text { sub-divided prefectures }\end{array}$ \\
\hline
\end{tabular}

Unless specified, the variables are independent variables

N.A., means not applicable

${ }^{\mathrm{a}}$ The industrial enterprises whose annual revenue of 20 million RMB or more from their main operations are regarded above designated size in statistic

${ }^{\mathrm{b}}$ The sum of retail sales of consumer goods sold by wholesale and retail, cate-ring and lodging to residents, social groups or institutions is total retail sale of consumer goods

2017a, b, c; Li et al., 2020). We postulate a positive relationship between resident income and LRDPpc.

3. Household deposits per capita (LHDPpc). The returns of assets and vested wealth is one of the basic sources and components of resident income. Household savings deposits can continue to bring capital returns, although it may be tiny compared to immovable property appreciation, but it is widespread for most residents. This variable is defined by the balance of savings deposits of rural and urban residents divided by the de facto population in each county or district area.

4. Built-up areas per capita (BUILTpc). It is widely acknowledged that region-specific degree of urbanization or the level of city scale has effects on resident income (Liang \& Gao, 2020; Yuan et al., 2020). The urban-rural divide is also regarded as a main type of income inequality in China (Wang et al., 2019a, b; Zhu et al., 2020). BUILTpc denotes the per capita share of built-up area in each county or district. It is designed to characterize the differences of local areas in urban intensity.

5. Industrial production (INDUS). As a basic economic activity, industrial production is closely related to the supply of jobs, fiscal taxation and the creation of wealth for the entire society. In the developing world, the larger the scale of manufacturing industry, the larger is the working opportunity and employment, which can benefit the overall livelihoods of people. So, the output value of industrial enterprises of each county or district is expected to be positively associated with resident income. 
6. Commerce prosperity (COMME). In addition to participating in production or processing, a considerable number of local residents are engaged in various business activities and operations. The profits generated in commodity transactions are the main source of income for business participators. So, commerce prosperity of each area is an important factor of people's livelihood and the variable is expected to have a high relationship with resident income.

7. Technological capacity (TECHN). Strong technological capacity in a region can markedly spur indigenous innovation, increase productivity and the general economic returns. The higher the degree of technological capacity, the higher is the profitability of social production. The scale of innovative activities implies the number of research \& development staffs engaged in technological creation. The high yield of regional innovations means that there are many hightech companies, organizations or communities in the area. This may be a foreseeable cause of regional inequality in resident income.

Since the purpose is to seek an explanation of geographic differences in resident income, crosssectional data analysis will be applied in the study to verify the hypothesis proposed earlier. The authenticity and explanatory power of the data are the basis of proofs in empirical research. Therefore, we use the original data without any mathematical transformation for the analysis. Taking account into the lag of economic effects, we use the 2018 data of explanatory variables and 2019 data of the dependent variable. We employ multicollinearity, autocorrelation, and heteroscedasticity tests to validate statistical assumptions of our regression models. And a general pooled regression model is specified as follows:

$$
\begin{aligned}
\text { DHINpc }_{i}= & \alpha_{i}+\beta_{1} \text { LRDPpc }_{i}+\beta_{2} \text { LHDPpc }_{i} \\
& +\beta_{3} \text { BUILTpc }_{i}+\beta_{4} \text { INDUS }_{i} \\
& +\beta_{5} \text { COMME }_{i}+\beta_{6} \text { TECHN }_{i}+\varepsilon_{i}
\end{aligned}
$$

where subscript $i$ refers to individual county or district, $\alpha$ is the intercept, $\beta_{i}$ is the regression estimator, and $\varepsilon_{i}$ is the error term.

\section{Study area}

Our empirical work starts in the Zhejiang Province. It is not only because of the economic leading status but also the distinctive intra-provincial inequality in Zhejiang. As shown in Fig. 1, Zhejiang is situated on the southeast coast of China with Hangzhou as the provincial capital. Although it is one of the smallest provincial administrative zones in China, Zhejiang is one of the most densely populated and wealthy areas as well. Zhejiang has the fourth largest economy in China, and is one of China's major export bases, accounting for around 13 percent of China's total exports (National Bureau of Statistics of China 2019). It was a pioneer in China's reform and opening-up, and carried out market-oriented reform more than 40 years ago, one of the first provinces in China to do so. Over the years, its private economy has achieved leapfrog growth in scale and strength, nurturing a great number of successful enterprises, and makes Zhejiang famous for mercantile culture in China. The region is noted for hills and waters, and the terrain slopes from southwest to northeast. The terrain is dominated by hills and mountains, accounting for $70.4 \%$ of the province's total area. Plains only account for $23.2 \%$, and most of them are concentrated in the northeast and coastal areas (Fig. 2). Due to the great terrain differences, the economic and social development of various parts of Zhejiang Province presents distinct regional inequalities. Under the interplay of the first and second nature causes, the northern plain area has been the economic and cultural centre of Zhejiang for hundreds of years, with densely distributed cities, population and strong industries, while the southern mountainous or hill areas are far less developed.

\section{Results and discussions}

Geographic polarization and clustering of resident income

We used the Moran's I and Getis-Ord General G statistics to evaluate the spatial distribution pattern of resident income in various areas of Zhejiang. The Moran's I statistic measures spatial autocorrelation based on both feature locations and feature values simultaneously. It calculates the Moran's I Index value and both a z-score and p-value to evaluate the significance of that Index. The General G statistic measures the concentration of high or low values for a given study area. It is a most appropriate tool when looking 


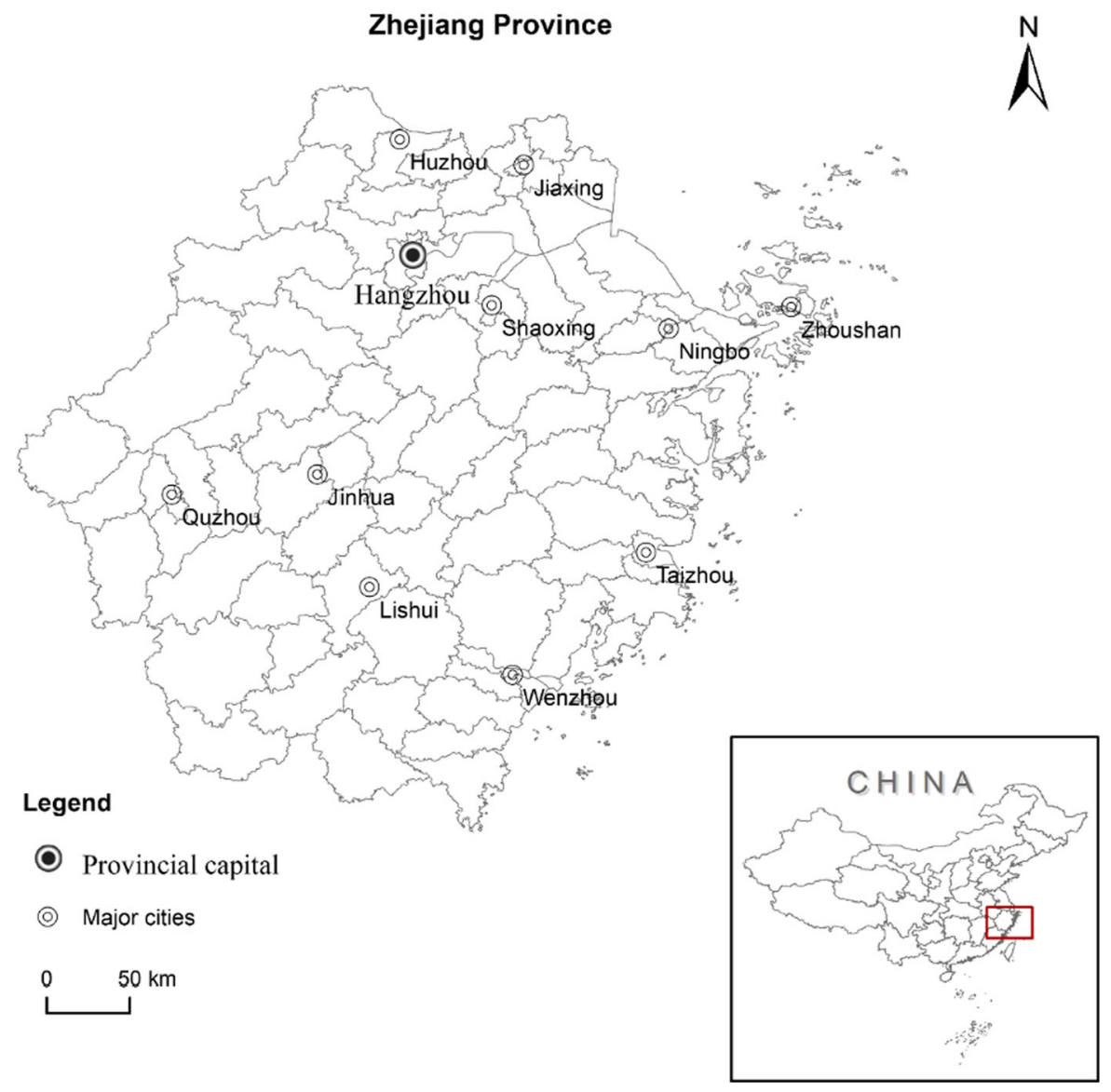

Fig. 1 The location and intra-provincial divisions of Zhejiang

for unexpected spatial spikes of high values. The results of our calculation (Table 2) show that for both indices, the p-value is statistically significant and the $\mathrm{z}$-score is positive. It means the null hypothesis of complete spatial randomness can be rejected. The implication of Moran's I tells us that spatial distribution of high values and/or low values in the dataset is more spatially clustered than would be expected if underlying spatial processes were truly random. The statistic of General $G$ further proves the spatial clustering of high values. The observed value of General G statistic is very little and approaching zero. That is because both the high and low values cluster tend to cancel each other out in the calculation. In another words, there exists both high and low-value clusters, but the degree or significance of high cluster is a little larger than that the low cluster.

Then, the Hot Spot Analysis (Getis-Ord Gi*) was used to calculate the Getis-Ord local statistic (z-score) for each feature in the dataset. This tool works by looking at each feature within the context of neighbouring features. And the results of z-scores and p-values can tell us where features with either high or low values cluster spatially. Although some general features of the spatial distribution of resident income have shown in the data plotting (Fig. 3), whether they are statistically significant remains to be tested. So, we used the Hot Spot Analysis to make such local autocorrelation test. The analysis result was displayed on the input map (Fig. 4). The hot spot (remarked red), with statistical significance, means a feature has a high value and be surrounded by other features with high values as well, which forms the high-value cluster spatially. The implication of cold spot (remarked blue) is just the converse version. The output results of our statistical calculation clearly show that the resident income levels within the study area show significant spatial divide and polarization. And there presents the 


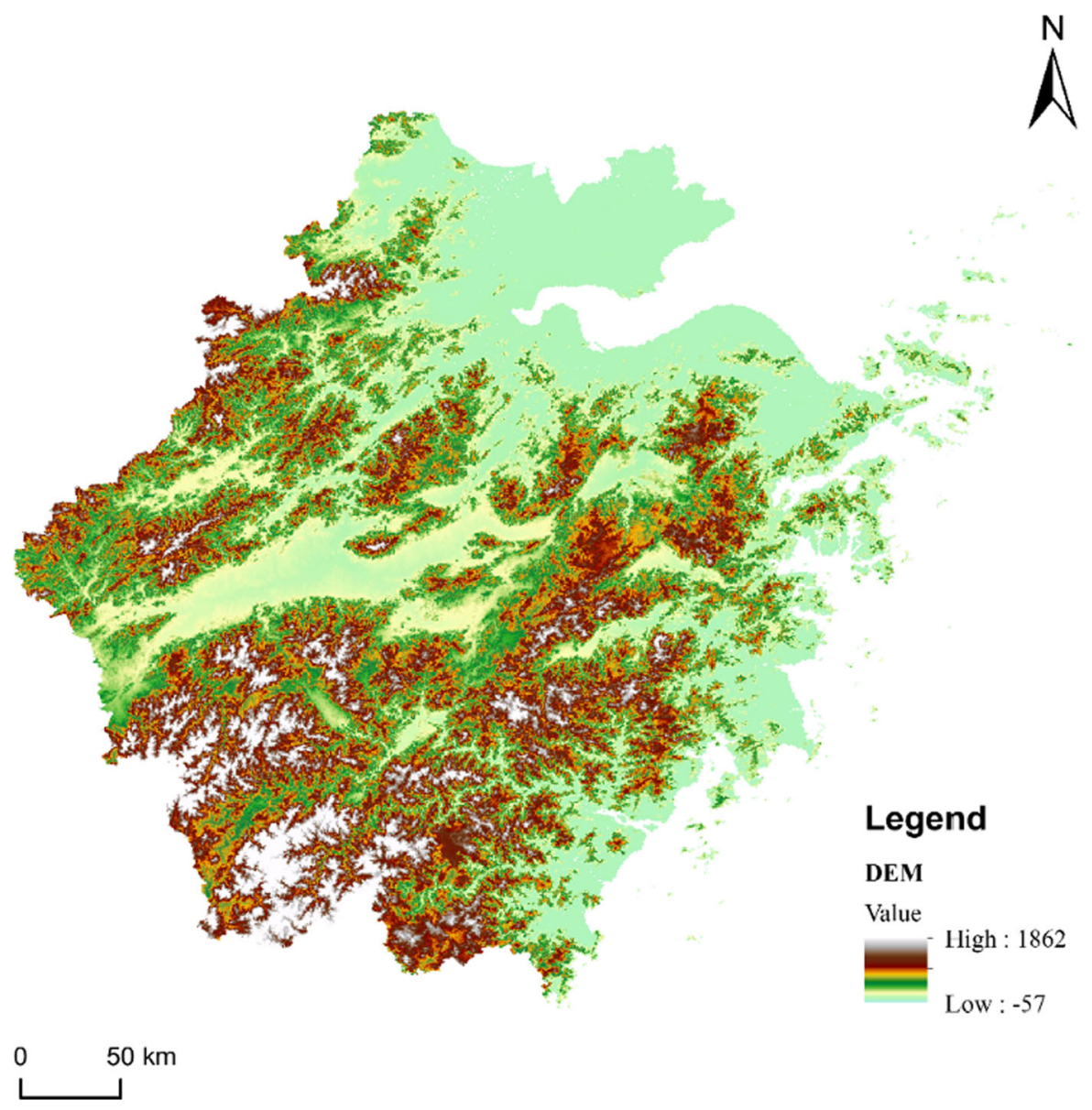

Fig. 2 The Digital Elevation Model (DEM) of Zhejiang (the data is downloaded from the website of Resource and Environment Science and Data Centre http://www.resdc.cn/)

Table 2 The results of Moran's I and Getis-Ord General G statistics

\begin{tabular}{|c|c|c|c|c|c|}
\hline Statistics & Observations & Expected value & Variance & Z-score & p-value \\
\hline Moran's I & 0.644 & -0.011 & 0.001 & 16.617 & 0.000 \\
\hline General G & 0.000005 & 0.000004 & 0.000 & 7.644 & 0.000 \\
\hline
\end{tabular}

The spatial statistics are carried out in the WGS84 $51 \mathrm{~N}$ projection coordinate system. The fixed distance band or threshold is set to $100 \mathrm{kms}$

diametrically opposite clusters, that is, the high-value cluster in the northeast and the low-value cluster in the southwest. The regional and environmental differences can provide a general explanation for such geographic gap in initial, that the northern part of Zhejiang is mostly plains with a large population and dense cities, while the southwest is mostly mountainous, with inconvenient transportation, sparse population and backward economy. These facts were widely mentioned by Wei and Ye (2004, 2005), Dai and Zhang (2011), and Yue et al. (2014).

Regional determinants of the income levels

In order to seek a regional-specific explanation for the resident income inequality, we applied the analytical 


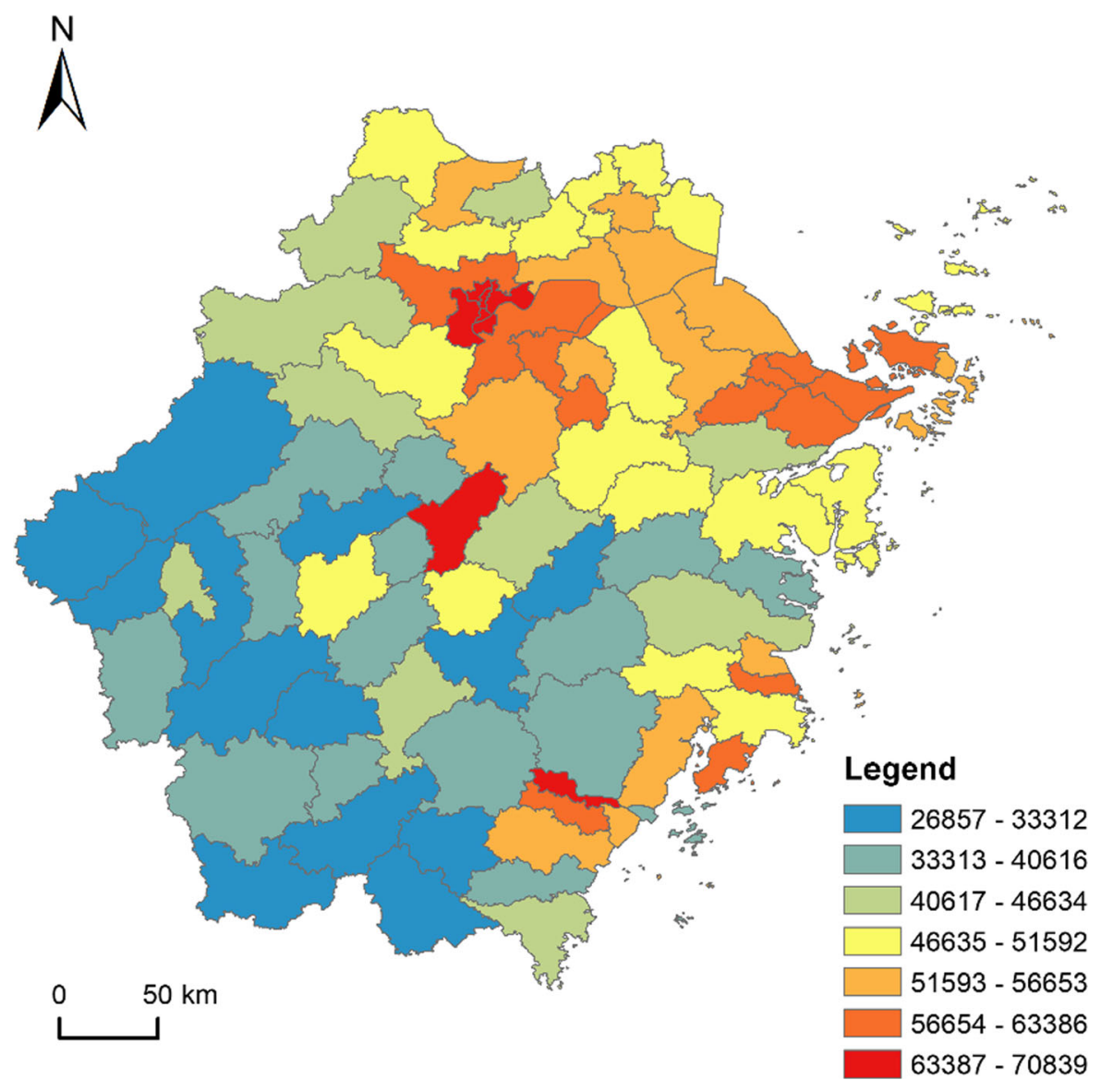

Fig. 3 The spatial distribution of resident income in Zhejiang measured by DHINpc (Unit: RMB/person, classified by Natural Breaks (Jenks))

model designed previously and the Ordinary least squares (OLS) method was used to perform the regression calculations. OLS is the best known of all regression techniques. It provides a global model of the variable or process we are trying to understand or predict. Prior to the data analysis, all possible violations of statistical assumptions were checked. And no heteroscedasticity and multicollinearity were detected. Table 3 summarizes the regression results generated after conducting the OLS estimation. Generally, results of the OLS diagnostics were satisfactory and show that the regression model is acceptable. The no significance of Koenker (BP) Statistic rejected the inconsistency hypothesis (either due to non-stationarity or heteroskedasticity) of the relationship modeled by us. To test for the overall model significance, Joint $F$-Statistic was examined and it proves the nearly $100 \%$ significance of the analytical model we built. The Jarque-Bera Statistic has no statistically significance. It rejected the statistical assumption that model predictions are biased (the residuals are not normally distributed). The adjusted $R^{2}$ value is 0.816 , indicating that the explanatory variables in the model explain most of values in the dependent variable. The Variance Inflation Factor (VIF) are all below the threshold (7.5) as consulted. It implies there is no notable issue of collinearity among all explanatory variables. Based on the regression coefficients, it can be found that the effect of most of the explanatory variables on resident income remains significant, except that the industrial production (INDUS). Builtup areas per capita (BUILTpc) and Commerce prosperity (COMME) have strong positive correlation with resident income levels of local areas particularly, which should be the major reason for the regional inequality of resident income. Besides, the correlation of technological capacity (TECHN) and the income level is much stronger than that of per capita regional 


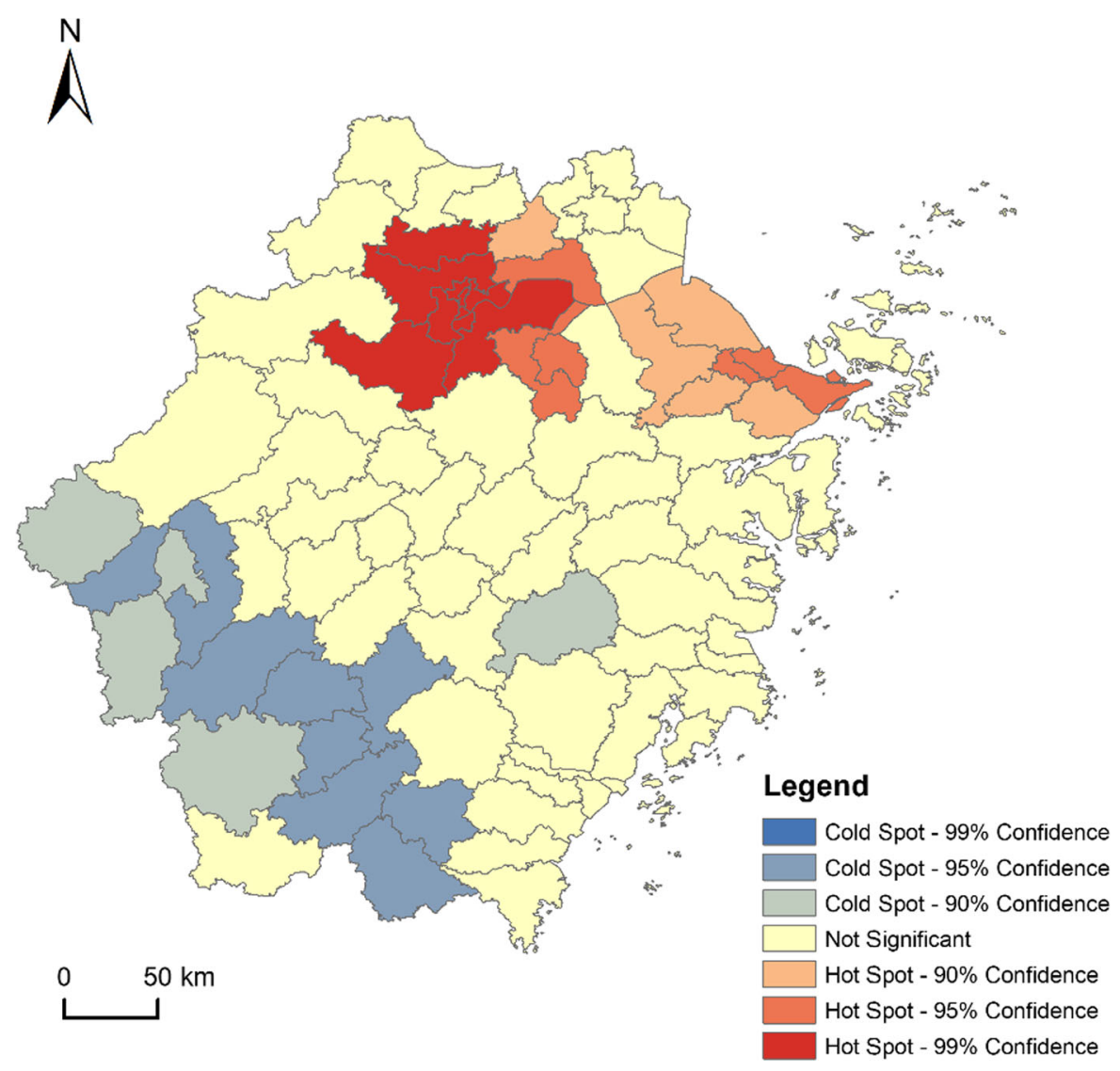

Fig. 4 The Getis-Ord local statistic for the resident income level in Zhejiang

Table 3 The results and diagnostics of OLS regression
*Significance at 0.1 ,

** Significance at 0.05 ,

$* * *$ Significance at 0.01

\begin{tabular}{llrrr}
\hline Variable & Coefficient & \multicolumn{1}{l}{ SE } & t-statistic & VIF \\
\hline LRDPpc & $0.086^{* * *}$ & 0.013 & 6.477 & 1.695 \\
LHDPpc & $0.052^{* *}$ & 0.025 & 2.057 & 2.215 \\
BUILTpc & $18.968^{*}$ & 11.853 & 1.600 & 1.155 \\
INDUS & 0.201 & 0.950 & 0.211 & 2.046 \\
COMME & $26.407^{* * *}$ & 3.726 & 7.087 & 2.220 \\
THCHN & $0.606^{* *}$ & 0.284 & 2.129 & 2.003 \\
Constant & $24,765.324^{* * *}$ & 1533.114 & 16.154 & - \\
Number of observations & 89 & & & \\
Adjusted $R^{2}$ value & 0.816 & & & \\
Joint -Statistic & $66.244^{* * *}$ & & & \\
Koenker $(B P)$ Statistic & 3.015 & & & \\
Jarque-bera statistic & 1.968 & & & \\
\hline
\end{tabular}

Implications of the regression results

Our statistical results regarding determinants of regional inequality in the resident income (Table 3) 
are analyzed more here. Based on both the strength and significance of the coefficient, commerce (scale or prosperity) is the most fundamental factor that determines the income level of local residents. Industrial production remains a positive correlation with resident income, but it fails to get the statistical significance compared with other variables. This finding concurs with those produced by Lardy (2016), who mentioned that the economic development in contemporary China is going towards a consumption-driven growth path. And this causes the commerce expansion and the rise in service industries. In the field survey of Zhejiang, we also found that quite a large number of local residents make life by wholesale and retail trades, catering and lodging services, which occupies a big share of regional employment. Although industrial production or manufacturing still contributes a lot to the national and regional economy, the almost unlimited supply of labor makes workers' wages very low, or namely cheap labor, as described by Lewis's twosector theory (Lewis, 1954). Also, there is a specific phenomenon of migrant workers in East China, as mentioned in many literatures (Gu et al., 2020; Yang et al., 2020), that many industrial enterprises depend much on the massive cheap labor from the middle and west of China, but few of them get registration in the local resident status. These should be the reasons why the assumption that industrial production affects the income level of local residents through employment and labor wage cannot be true.

The observed effect of BUILTpc on HDINpc is the second highest among that the explanatory variables, and it is more than $90 \%$ significant. It confirms our hypothesis that the geographic difference in urban intensity has an impact on resident income. The coefficient of TECHN is much smaller than that the COMME and BUILTpc, but it still has a certain strength with more than $95 \%$ significance. This confirms the positive contribution of technological capability to resident income levels of local areas, and implies technological innovation can not only drive regional economic growth but bring additional economic benefits to the people's livelihood. Besides, although the significant correlation with HDINpc, the coefficient of LRDPpc and LHDPpc are incredibly tiny and even not in the same order of magnitude compared with that the other variables. It means the impact of the regional disparity in general (wealth or development) on the disposable income of local residents is very limited. This may be a consequence of the still strong public sector in Chinese regional economy. In the case, the resident disposable income is often out of sync with or lagging behind the regional development and economic growth, as the government, state-owned enterprises and relevant organizations have a large share in the social wealth allocation.

\section{Conclusions}

This study supplements research findings on resident income inequality in China with the geographic pattern detection and econometric analysis of the local areas in Zhejiang. Our own findings may deepen the knowledge, and help scholars or policymakers come to understand the regional inequality in resident income and its determinants at the county or district level of China. The geographic characteristics of the income distribution in the study area have been revealed as well, that the significant spatial polarization and clusters. It means the great regional gap of resident income in local areas. The disposable income of local residents is mainly influenced by the regional commerce prosperity, urban intensity and technological capacity. But industrial production does not have a significant correlation with the income levels, as supposed. Other factors such as LRDPpc and LHDPpc are less important. This is consistent with the employment status of the grassroots in China. That quite a large part of local residents make life and acquire wealth by diverse commercial activities like trades, services or business operations.

Concomitantly, our empirical results may offer some hints for narrowing income gap, pushing regional convergence, and achieving common wealth. First, in order to effectively increase the resident income in poverty-stricken areas, the focus on accelerating up industrial development is not sufficient for the government in the current situation, and how to better the business environment and facilitate the growth of regional commerce should get more attention. Some advanced communication technologies or methods are useful to spread the commercial propaganda (e.g., tourism, investment and exhibition) and enlarge trade channels of local firms. This has been proved by many recent literatures (Couture et al., 2021; Muktar et al., 2018; Wei et al., 2020a, b) that the positive role of ICTs and E-commerce in local 
business and people's livelihoods. Second, Urban construction still deserves attention for local states, especially in rural or less-developed areas. The increase in the built-up density based on population size can contribute to the agglomeration of economic factors or resources, and produce positive effects on resident income. Third, for metropolitan and developed areas, technological innovation should be the focus of them in pursuit of higher income. Meanwhile, extra effort can be made to push the regional cooperation system of innovative activities. This can promote the spatial spillover of technological capabilities, drive the leapfrog development of backward areas, and narrow the widening trend of income gap hopefully. Last but not the least, for most developing countries or regions, although industrialization is a necessary process, the government should still strive for economic diversification, and indigenous innovation in particular, rather than over-reliance on manufacturing, especially low-tech processing industry. This can prevent falling into the low-income or poverty traps and benefit the long-term well-being of the people.

\section{Funding Not applicable}

Availability of data and material The data involved in this article comes from the statistical yearbooks of local authorities, and the author can provide them if requested.

\section{Declarations}

Conflicts of interest The author declare that they have no conflicts of interest.

Open Access This article is licensed under a Creative Commons Attribution 4.0 International License, which permits use, sharing, adaptation, distribution and reproduction in any medium or format, as long as you give appropriate credit to the original author(s) and the source, provide a link to the Creative Commons licence, and indicate if changes were made. The images or other third party material in this article are included in the article's Creative Commons licence, unless indicated otherwise in a credit line to the material. If material is not included in the article's Creative Commons licence and your intended use is not permitted by statutory regulation or exceeds the permitted use, you will need to obtain permission directly from the copyright holder. To view a copy of this licence, visit http://creativecommons.org/licenses/by/4.0/.

\section{References}

Anderson, G., Hao, T., \& Pittau, M. G. (2019). More unequal yet more alike, the changing patterns of family formation, generational mobility and household income inequality in China: A counter-factual analysis. The Journal of Economic Inequality, 17(3), 359-378.

Couture, V., Faber, B., Gu, Y., \& Liu, L. (2021). Connecting the countryside via E-Commerce: Evidence from China. American Economic Review: Insights, 3(1), 35-50.

Dai, X., \& ZHANG, J. . (2011). The TOPSIS analysis on regional disparity of economic development in zhejiang province. Canadian Social Science, 7(5), 135-139.

Gao, J., Liu, Y., Chen, J., \& Cai, Y. (2019a). Demystifying the geography of income inequality in rural China: A transitional framework. Journal of Rural Studies. https://doi.org/ 10.1016/j.jrurstud.2019.01.010

Gao, Q., Yang, S., \& Zhai, F. (2019b). Social policy and income inequality during the Hu-Wen Era: A Progressive Legacy? The China Quarterly, 237, 82-107.

Getis, A., \& Ord, J. K. (2010). The analysis of spatial association by use of distance statistics. In Luc Anselin \& Sergio J. Rey (Eds.), Perspectives on spatial data analysis (pp. 127-145). Berlin, Heidelberg: Springer.

Gu, H., Liu, Z., \& Shen, T. (2020). Spatial pattern and determinants of migrant workers' interprovincial hukou transfer intention in China: Evidence from a national migrant population dynamic monitoring survey in 2016. Population, Space and Place, 26(2), e2250.

Hao, R., \& Wei, Z. (2010). Fundamental causes of inlandcoastal income inequality in post-reform China. The Annals of Regional Science, 45(1), 181-206.

He, C., Zhou, Y., \& Zhu, S. (2017a). Firm dynamics, institutional context, and regional inequality of productivity in China. Geographical Review, 107(2), 296-316.

He, S., Bayrak, M. M., \& Lin, H. (2017b). A comparative analysis of multi-scalar regional inequality in China. Geoforum, 78, 1-11.

He, S., Fang, C., \& Zhang, W. (2017c). A geospatial analysis of multi-scalar regional inequality in China and in metropolitan regions. Applied Geography, 88, 199-212.

He, S., Liao, F. H., \& Li, G. (2019). A spatiotemporal analysis of county economy and the multi-mechanism process of regional inequality in rural China. Applied Geography, $111,102073$.

Huang, H., \& Wei, Y. D. (2019). The spatial-temporal hierarchy of inequality in urban China: A prefectural city-level study. The Professional Geographer, 71(3), 391-407.

Iacob N, Koch-Weser. (2013). The Reliability of China's Economic Data: An Analysis of National Output. https://www. uscc.gov/sites/default/files/Research/

TheReliabilityofChina'sEconomicData.pdf. Accessed 24 Nov. 2020.

Lardy, N. R. (2016). China: Toward a consumption-driven growth path. In Seeking changes: The economic development in contemporary China (pp. 85-111).

Leng, C., Ma, W., Tang, J., \& Zhu, Z. (2020). ICT adoption and income diversification among rural households in China. Applied Economics, 52, 3614-3628. 
Lewis, W. A. (1954). Economic development with unlimited supplies of labor. Journal of the Manchester School of Economics and Social Studies, 20, 139-192.

Li, F., \& Li, G. (2018). Agglomeration and spatial spillover effects of regional economic growth in China. Sustainability, 10(12), 4695.

Li, G., \& Fang, C. (2014). Analyzing the multi-mechanism of regional inequality in China. The Annals of Regional Science, 52(1), 155-182.

Li, H., Wei, Y. D., \& Swerts, E. (2020). Spatial inequality in the city-regions in the Yangtze River Valley China. Urban Studies, 57(3), 672-689.

Li, S., \& Sicular, T. (2014). The distribution of household income in China: Inequality, poverty and policies. The China Quarterly, 217, 1-41.

Li, Y. (2020). Empirical analysis of the impact of financial development on the income gap between urban and rural residents in the context of large data using fuzzy Kmeans clustering algorithm. The International Journal of Electrical Engineering \& Education. https://doi.org/10.1177/ 0020720920936837

Liang, Y., \& Gao, Z. (2020). Effects of city scale's expansion on urban residents' income growth: Based on the empirical evidence of CHIP 2009. ICCREM 2020: Intelligent construction and sustainable buildings (pp. 353-359). American Society of Civil Engineers.

Liao, F. H., Wei, Y. D., \& Huang, L. (2020). Regional Inequality in Transitional China. Routledge.

Liu, Y., Lu, M., \& Xiang, K. (2018). Balance through agglomeration: A race between geography and policy in China's regional development. China \& World Economy, 26(6), 72-96.

Luo, C., Li, S., \& Sicular, T. (2020). The long-term evolution of national income inequality and rural poverty in China. China Economic Review, 62, 101465.

Ma, X., Wang, F., Chen, J., \& Zhang, Y. (2018). The income gap between urban and rural residents in China: Since 1978. Computational Economics, 52(4), 1153-1174.

Mitchel, A. (2005). The ESRI Guide to GIS analysis, Volume 2: Spartial measurements and statistics. ESRI Guide to GIS analysis.

Molero-Simarro, R. (2017). Inequality in China revisited. The effect of functional distribution of income on urban top incomes, the urban-rural gap and the Gini index, 1978-2015. China Economic Review, 42, 101-117.

Muktar, B. G., Man, N., Saleh, J. M., \& Daneji, M. I. (2018). Evaluation of ICTs access, use and preferences for livelihood resilience: Results from a survey of Malaysian fisher folks. The Journal of Agricultural Education and Extension, 24(4), 377-388.

Naughton, B. (2007). The Chinese economy. Transitions and growth. MIT Press.

Paul, S., Chen, Z., \& Lu, M. (2017). Contribution of household income components to the level and rise of inequality in urban China. Journal of the Asia Pacific Economy, 22(2), 212-226.

Su, C. W., Song, Y., Ma, Y. T., \& Tao, R. (2019). Is financial development narrowing the urban-rural income gap? A cross-regional study of China. Papers in Regional Science, 98(4), 1779-1800.
Sutherland, D., \& Yao, S. (2011). Income inequality in China over 30 years of reforms. Cambridge Journal of Regions, Economy and Society, 4(1), 91-105.

Tian, X., Zhang, X., Zhou, Y., \& Yu, X. (2016). Regional income inequality in China revisited: A perspective from club convergence. Economic Modelling, 56, 50-58.

Wang, C., Wan, G., \& Yang, D. (2014). Income inequality in the People's Republic of China: Trends, determinants, and proposed remedies. Journal of Economic Surveys, 28(4), 686-708.

Wang, S., Tan, S., Yang, S., Lin, Q., \& Zhang, L. (2019). Urbanbiased land development policy and the urban-rural income gap: Evidence from Hubei Province China. Land Use Policy, 87, 104066.

Wang, X., Shao, S., \& Li, L. (2019b). Agricultural inputs, urbanization, and urban-rural income disparity: Evidence from China. China Economic Review, 55, 67-84.

Wang, Y., Li, Y., Huang, Y., Yi, C., \& Ren, J. (2020). Housing wealth inequality in China: An urban-rural comparison. Cities, 96, 102428.

Wei, Y. D., Li, H., \& Yue, W. (2017). Urban land expansion and regional inequality in transitional China. Landscape and Urban Planning, 163, 17-31.

Wei, Y. D., Lin, J., \& Zhang, L. (2020b). E-commerce, taobao villages and regional development in China. Geographical Review, 110(3), 380-405.

Wei, Y. D., Wu, Y., Liao, F. H., \& Zhang, L. (2020). Regional inequality, spatial polarization and place mobility in provincial China: A case study of Jiangsu province. Applied Geography, 124, 102296.

Wei, Y. D., \& Ye, X. (2004). Regional inequality in China: A case study of Zhejiang province. Tijdschrift Voor Economische En Sociale Geografie, 95(1), 44-60.

Wooldridge, J. M. (2006). Introductory econometrics: A modern approach (3rd ed.). Thomson Press.

Wu, J. X., \& He, L. Y. (2018). Urban-rural gap and poverty traps in China: A prefecture level analysis. Applied Economics, 50(30), 3300-3314.

Xiang, Z., Ban, P., \& Yuan, Q. (2020). Measurement of the income difference of rural residents in peri-urbanized areas and its influencing Factors: Evidence from Nanhai, Foshan, China. Sustainability, 12(20), 8382.

Xie, Y., \& Jin, Y. (2015). Household wealth in China. Chinese Sociological Review, 47(3), 203-229.

Xie, Y., \& Zhou, X. (2014). Income inequality in today's China. Proceedings of the National Academy of Sciences, 111(19), 6928-6933.

Yang, J., Gunderson, M., \& Li, S. (2020). The impact of minimum wages on migrant workers' wages. In Shi Li \& Carl Lin (Eds.), Minimum Wages in China (pp. 145-164). Singapore: Palgrave Macmillan.

Ye, X., \& Wei, Y. D. (2005). Geospatial analysis of regional development in China: The case of Zhejiang Province and the Wenzhou model. Eurasian Geography and Economics, 46(6), 445-464.

Yuan, Y., Wang, M., Zhu, Y., Huang, X., \& Xiong, X. (2020). Urbanization's effects on the urban-rural income gap in China: A meta-regression analysis. Land Use Policy, 99, 104995.

Yue, W., Zhang, Y., Ye, X., Cheng, Y., \& Leipnik, M. R. (2014). Dynamics of multi-scale intra-provincial regional 
inequality in Zhejiang China. Sustainability, 6(9), 5763-5784.

Zeng, C., Song, Y., He, Q., \& Liu, Y. (2018). Urban-rural income change: Influences of landscape pattern and administrative spatial spillover effect. Applied Geography, 97, 248-262.

Zhang, Q., Bilsborrow, R. E., Song, C., Tao, S., \& Huang, Q. (2019). Rural household income distribution and inequality in China: Effects of payments for ecosystem services policies and other factors. Ecological Economics, 160, 114-127.

Zhang, W. (2020). The important breakthrough in the theory of socialist residents' income distribution-The participation in distribution according to production factors and the debate on the issue of the relationship between fairness and efficiency. In Zhuoyuan Zhang (Ed.), Historical perspectives on chinese economics (1949-2011) (pp. 401-421). Singapore: Springer.

Zhu, S., Yu, C., \& He, C. (2020). Export structures, income inequality and urban-rural divide in China. Applied Geography, 115, 102150.

Publisher's Note Springer Nature remains neutral with regard to jurisdictional claims in published maps and institutional affiliations. 